\title{
Theory and Practice of Heat Transfer in Electric Arc and Flare Furnaces and Power Plants
}

\author{
Anatoliy Nikolaevich Makarov \\ Department of Electrical Supply and Electrical Engineering, Tver State Technical University, Tver, Russia \\ Email: tgtu_kafedra_ese@mail.ru
}

How to cite this paper: Makarov, A.N. (2020) Theory and Practice of Heat Transfer in Electric Arc and Flare Furnaces and Power Plants. World Journal of Engineering and Technology, 8, 739-755. https://doi.org/10.4236/wjet.2020.84053

Received: September 5, 2020

Accepted: November 15, 2020

Published: November 18, 2020

Copyright $\odot 2020$ by author(s) and Scientific Research Publishing Inc. This work is licensed under the Creative Commons Attribution-NonCommercial International License (CC BY-NC 4.0). http://creativecommons.org/licenses/by-nc/4.0/ (c) (i) (5) Open Access

\begin{abstract}
The author describes the fundamental laws of physics, the laws of thermal radiation of ionized and non-ionized gas volumes. Based on open laws, a modern theory of heat transfer and methods for calculating heat transfer in electric arc and flare metallurgical furnaces, furnaces of steam boilers, and combustion chambers of gas turbine plants of power plants have been developed. The use of scientific discovery makes it possible to create innovative electric arc steel-smelting furnaces, flare heating furnaces, and combustion chambers in which the consumption of electricity and fuel is reduced, productivity and service life are increased, and the amount of harmful emissions into the environment is reduced.
\end{abstract}

\section{Keywords}

Heat Transfer, Thermal Radiation, Electric Arc, Torch, Furnaces, Fire Chambers, Combustion Chambers

\section{Introduction}

Heat transfer by radiation is the main type of heat transfer in torch heating furnaces, fire chambers of boilers, the combustion chambers (CC) of gas-turbine installations (GTI). Thermal flows falling on the heating surface from the flare formed during combustion of gas, oil, pulverized coal fuel by $92 \%$ - $98 \%$ consist of heat radiation flow and by $2 \%-8 \%$ from convective flow [1] [2] [3] [4] [5]. Flame transmits $99 \%$ - $99.5 \%$ heat with radiation, $0.5 \%-1 \%$ by convection [5].

Existing methods for calculating heat transfer such as zonal, numerical, $\mathrm{Pl}$ approximation, Monte Carlo, Schuster-Schwarzschild, Eddington, Chandrasekhar, spherical harmonics and others use the Stefan-Boltzmann law of heat radiation from solids. However, the radiation from gas volumes of electric arcs and 
torches is not subject to the Stefan-Boltzmann law of radiation from solids and the calculation error is $70 \%-90 \%$ or more.

In the twentieth century in articles, monographs, textbooks of Russian and foreign scientists, designers century, there was no data on the causes of uneven wear and low resistance of the lining of the walls, the arch of electric arc steel melting furnaces, uneven melting of the charge, the temperature of the metal around the perimeter due to the lack of the laws of heat radiation from gas volumes and the inability to accurately calculate the heat transfer. There were no results of the calculation of the distribution of the heat radiation fluxes from the torch along the height and perimeter of the furnaces, the burner device. There was no explanation for the unevenness of vaporization and deposits in the pipes. There were no data on the distribution of heat fluxes on all surfaces, faces and height of heated products in torch furnaces. There were no calculated data on the distribution of the heat radiation fluxes from the torch along the flame tube and the burner device of the combustion chambers.

The lack of accurate data of heat transfer calculations was compensated by the results of numerous, expensive, time-consuming, long-term experimental studies of heat transfer and technical modes of operation of electric arc steelmaking and torch furnaces, fire boxes, combustion chambers.

At the end of the 20th century, the laws of heat radiation from gas volumes, the laws of heat radiation from electric arcs of steel melting furnaces and torches of heating furnaces, fire boxes, combustion chambers of gas turbine power plants were discovered. The disclosed laws of heat radiation from gas volumes, as well as the laws of heat radiation from solids of Planck, Wien, Stefan-Boltzmann, belong among the fundamental laws of physics which have multidisciplinary and applicability in various fields of science and technology.

The discovery of the fundamental law of physics is an outstanding event in the history of mankind and takes place on average once in 50 - 80 years. Physics textbooks for schools and universities, which set out a little more than 30 laws discovered by humankind for three thousand years, since the third century BC from the law of Archimedes and to the last fundamental laws, postulates discovered by Bohr in 1913 are proof of this.

\section{The Laws of Thermal Radiation of Gas Volumes}

In 1996-2001, the author A.N. Makarov discovered the fundamental laws of physics, the laws of thermal radiation of gas volumes of flares (Figure 1), the laws of radiation of cylindrical gas volumes (Table 1) [5] [6] [7] [8]. To comply with centuries-old scientific traditions and copyright laws of thermal radiation of gas volumes of torches in a diploma for scientific discovery, articles, textbooks, monographs are similar to the laws of radiation of an absolute black body (ABB), the laws of Stefan-Boltzmann, Planck, Wien, are named after the author, their discovered by the laws of Makarov. Based on a scientific discovery, the author developed the theory and methods of calculating heat transfer [5]-[15] in 


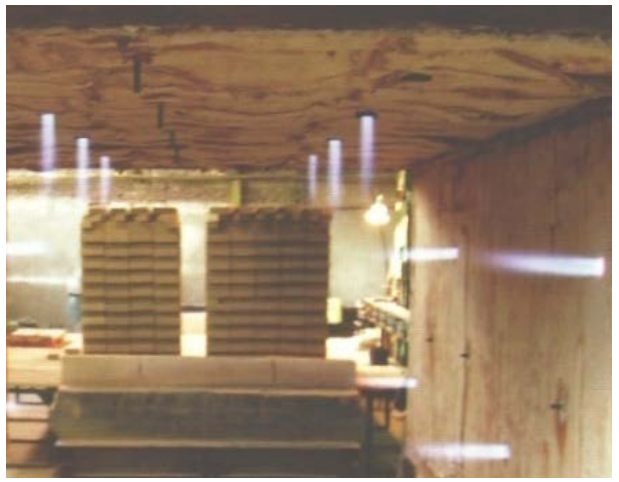

(a)

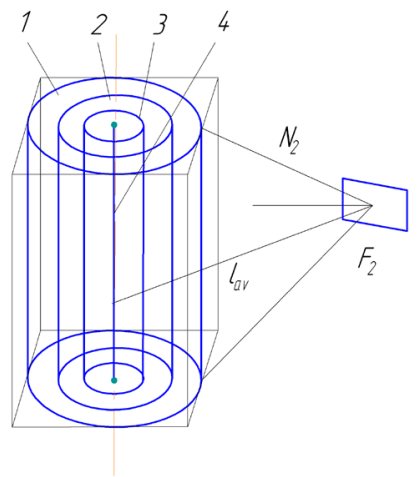

(b)

Figure 1. Flare brick kiln (a), radiation from coaxial cylinder gas volumes $1-4$ on the calculation area $\mathrm{F}_{2}(\mathrm{~b})$.

Table 1. The laws of thermal radiation of gas volumes of torches (Makarov's laws).

\begin{tabular}{|c|c|c|}
\hline Law number & Mathematical record of the law & Formulation of the law \\
\hline 1 & $q_{F d F}=\frac{\phi_{F_{0} d F} \cdot P_{F} \cdot \mathrm{e}^{-k l}}{F_{0}}=\frac{\phi_{F_{0} d F} \cdot P_{F}}{F_{0} \cdot \mathrm{e}^{k l}}$ & $\begin{array}{l}\text { The density of the flux of thermal } \\
\text { radiation incident from the cylindrical } \\
\text { gas volume to the computational site is } \\
\text { directly proportional to its power, the } \\
\text { angular emissivity, and inversely } \\
\text { proportional to the absorption } \\
\text { coefficient, the average path length of } \\
\text { the rays from all volume atoms to the } \\
\text { site and the area of the site. }\end{array}$ \\
\hline 2 & $l_{1}=l_{2}=l_{3}=\cdots=l_{i}=\left(\sum_{i=1}^{n} \frac{l_{i}}{n}\right)=l$ & $\begin{array}{l}\text { The average path length of the rays from } \\
\text { the quadrillion radiating volume atoms } \\
\text { to the calculated area is equal to the } \\
\text { arithmetic mean distance from the axis } \\
\text { of symmetry of the volume to the site. }\end{array}$ \\
\hline 3 & $\phi_{F_{i} d F}=\phi_{F_{2} d F}=\phi_{F_{3} d F}=\cdots=\phi_{F_{d} d F}$ & $\begin{array}{l}\text { Angular coefficients of radiation of } \\
\text { coaxial cylindrical gas volumes to the } \\
\text { design site are equal. }\end{array}$ \\
\hline 4 & $q_{F_{1} d F}=q_{F_{2} d F}=q_{F_{3} d F}=\cdots=q_{F_{i} d F}$ & $\begin{array}{l}\text { The density of the radiation fluxes of } \\
\text { coaxial cylindrical gas volumes to the } \\
\text { calculation site are equal. }\end{array}$ \\
\hline 5 & $q_{F_{d} d F}=\sum_{i=1}^{n} q_{F_{i} d F}$ & $\begin{array}{l}\text { The densities of the thermal radiation } \\
\text { fluxes of a cylindrical gas volume of } \\
\text { large diameter and its cylindrical axis of } \\
\text { symmetry to the calculation site are } \\
\text { equal when the heat power released } \\
\text { in them are equal. }\end{array}$ \\
\hline
\end{tabular}

flare furnaces, furnaces of steam boilers, combustion chambers of gas turbine plants, gas turbine engines (GTE) of civil aviation.

In Table 1, the following notation is used: $\mathrm{q}$ is the flux density of thermal radiation incident from the cylindrical gas volume at the design site, $\mathrm{kW} / \mathrm{m}^{2} ; \varphi$ are the angular emission coefficients (radiation fraction) of the cylindrical gas volume at the design site; $\mathrm{P}$ is the radiation power of a cylindrical gas volume, $\mathrm{kW}$; 
$\mathrm{k}$ is the absorption coefficient of the cylindrical gas volume; $\mathrm{l}$ is the average path length of the rays from all atoms of the cylindrical gas volume to the calculated site, $\mathrm{m} ; \mathrm{F}$ is the surface area of the calculation site, $\mathrm{m}^{2}$; indices indicate the numbers of gas volumes from 1 to $\mathrm{n}$.

With the discovery of the laws of thermal radiation of gas volumes, the extremely complex problem of calculating with the help of one formula for the emission of quadrillion torch atoms to any calculation site in furnaces, furnaces, and combustion chambers has been solved.

In 2014-16 the author of this article disclosed the laws of heat radiation from isothermal isochoric concentric spherical gas volumes, that the article presents. Radiating gas volumes of any complex form can be entirely filled by concentric spherical together with coaxial cylinder gas volumes and calculate heat radiation from gas volumes, furnace torches, fire boxes, combustion chambers on the heating surfaces with high accuracy.

Miscalculation in modeling heat radiation from gas volume in the form of parallelepiped by one cylindrical gas volume is $2.3 \%, 15$ spherical gas volumes is $2.2 \%, 108$ spherical gas volumes is $0.9 \%, 432$ spherical gas volumes is $0.4 \%$.

Thus, gas volume in the form of parallelepiped can be modeled by cylindrical gas volume, one-two hundred spherical gas volumes and obtain the results from calculations with high accuracy.

\section{The Basics of the Developed Theory and Methodology for Calculating Heat Transfer in Electric Arc Furnaces, Flare Furnaces, and Combustion Chambers}

The disclosed laws are multidisciplinary and are used in metallurgy, energy, and various industries. According to open laws, cylindrical gas volumes are inscribed in the gas volumes of torches (Figure 2(b)), the radiation of which in the calculations is modeled by the equivalent radiation of their cylindrical axis of symmetry (see law V, Table 1).

The main formulas of the calculation method for heat transfer in electric arc furnaces, flare furnaces, and combustion chambers are set out in Table 2.

In Table 2 the following conventions are used: $q_{\text {in }}$ is the density of the heat flux incident on the $i$-th elementary area on the heating surface, $q_{\text {int }}$ is the density of the heat flux incident on the $i$-th area from the torch, taking into account the

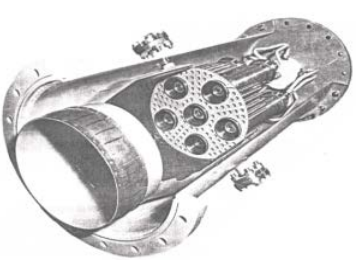

(a)

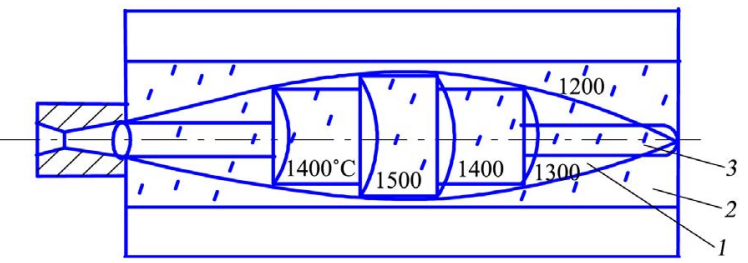

(b)

Figure 2. GTP combustion chamber (a), geometric model of a torch in the form of cylindrical gas volumes (b): 1-torch; 2-combustion products; 3-cylindrical gas volumes of different diameters. 
Table 2. Equations, formulas for calculating heat transfer in flare furnaces, combustion chambers according to the laws of radiation of gas volumes.

\begin{tabular}{|c|c|c|c|}
\hline 1 & $\begin{array}{l}\text { The density of the total heat flux } \\
\text { incident on the calculated area }\end{array}$ & $q_{i n}=q_{\text {int }}+q_{i n r t}+q_{i n s}+q_{i n r s}+q_{i c o n}+q_{i c p}$ & $\mathrm{~kW} / \mathrm{m}^{2}$ \\
\hline 2 & $\begin{array}{l}\text { The fraction of power released in the } \\
\text { gas volume of the torch }\end{array}$ & $P_{1}: P_{2}: \cdots: P_{n}=T_{1}^{3} V_{1}: T_{2}^{3} V_{2}: \cdots: T_{n}^{3} V_{n}$ & \\
\hline 3 & $\begin{array}{l}\text { The density of the heat flux of radiation } \\
\text { incident on the calculated area from the } \\
\text { torch (the first law of heat radiation } \\
\text { from cylindrical gas volumes) }\end{array}$ & $q_{i n t}=\sum_{1}^{n} \frac{\phi_{t i j} P_{t j}}{F_{i}} \mathrm{e}^{-k l}$ & $\mathrm{~kW} / \mathrm{m}^{2}$ \\
\hline 4 & $\begin{array}{l}\text { The density of the heat flux of radiation } \\
\text { caused by the reflection of the torch } \\
\text { radiation from the surfaces to the } \\
\text { calculated area }\end{array}$ & $q_{i m t}=\sum_{1}^{n} \frac{P_{i j} \psi_{j k}-\phi_{i j k} \mathrm{e}^{-k l}}{F_{k}}$ & $\mathrm{~kW} / \mathrm{m}^{2}$ \\
\hline 5 & $\begin{array}{l}\text { The density of the heat flux of radiation } \\
\text { incident on the calculated area from } \\
\text { the radiating surfaces }\end{array}$ & $q_{i n s}=\sum_{1}^{n} \frac{\phi_{j i} Q_{j s}}{F_{i}} \mathrm{e}^{-k l}$ & $\mathrm{~kW} / \mathrm{m}^{2}$ \\
\hline 6 & $\begin{array}{l}\text { The density of the heat flux of radiation } \\
\text { caused by the reflection of radiation } \\
\text { from the surfaces and incident on } \\
\text { the calculated area }\end{array}$ & $q_{i n r s}=\sum_{1}^{n} \frac{Q_{j s}\left(\psi_{j k}-\phi_{j k}\right) \mathrm{e}^{-k l}}{F_{k}}$ & $\mathrm{~kW} / \mathrm{m}^{2}$ \\
\hline 7 & $\begin{array}{l}\text { The density of the convective flux from } \\
\text { the torch and products of combustion } \\
\text { on the calculated area }\end{array}$ & $q_{i c o n}=\alpha_{c o n}\left(t_{g a v}-t_{p}\right)$ & $\mathrm{kW} / \mathrm{m}^{2}$ \\
\hline 8 & $\begin{array}{l}\text { The density of radiation fluxes from } \\
\text { products of combustion on the } \\
\text { calculated area }\end{array}$ & $q_{i c p}=\sum_{1}^{n} \frac{\phi_{c p i j} P_{c p j}}{F_{i}} \mathrm{e}^{-k l}$ & $\mathrm{~kW} / \mathrm{m}^{2}$ \\
\hline 9 & $\begin{array}{l}\text { The flux of the corresponding } \\
\text { surface radiation }\end{array}$ & $Q_{j s}=\varepsilon_{j} c_{s}\left(T_{j} / 100\right)^{4} F_{j}$ & $\mathrm{~kW}$ \\
\hline
\end{tabular}

absorption of the torch radiation; $q_{\text {inrt }}$ is the flux density of thermal radiation incident on the $i$-th area $\mathrm{b}$ caused by the reflection of the torch radiation from the walls, the hearth, the arch, products; $q_{\text {ins }}$ is the flux density of thermal radiation incident on the $i$-th site from the radiating walls, the hearth, the lid, taking into account the reflection and absorption of radiation; $q_{\text {inrs }}$ - the flux density of thermal radiation incident on the $i$-th site, caused by the reflection of surface radiation from walls, hearths, lids, ingots; $q_{\text {icon }}$-convective flow density of the torch and combustion products of the i-th site; $q_{i c p}$ is the radiation flux density of the combustion products to the $i$-th site, $\varphi_{t j i}$ is the local angular coefficient of radiation of the $j$-th cylindrical source to the i-th site, $P_{t j}$ is the power of the $j$-th cylindrical source, $F_{i}$ is the area of the $i$-th elementary area, $\psi_{t j k}$ is generalized angular emissivity of the $\mathrm{j}$-th volume zone ( $j$-th cylindrical source) to the $k$-th surface, $\varphi_{t j k}$ is the average angular emissivity of the $j$-th cylindrical source to the $k$-th surface, $\varphi_{j i}$ is the local angular emissivity of the $j$-th surface on $i$-th platform, $Q_{j s}$-self-radiation flux of the $j$-th surface, $t_{p}=20^{\circ} \mathrm{C}$ - product temperature; $t_{g a v}=$ $1400^{\circ} \mathrm{C}$-average temperature of combustion products, gas; $\alpha_{c o n}-$ heat transfer coefficient by convection, with free convection $\alpha_{c o n}=11.6 \mathrm{~kW} /\left(\mathrm{m}^{2} \cdot{ }^{\circ} \mathrm{C}\right)$; at the 
beginning of heating, $q_{i c o n}=16.2 \mathrm{~kW} / \mathrm{m}^{2}, \varphi_{c p j i}$ is the local angular emissivity of the $j$-th volume of combustion products to the $i$-th site, $P_{c p j}$ is the power of the $j$-th volume of combustion products, $\varepsilon_{j}$ is the emission coefficient of the $j$-th surface; $c_{s}$ is the emissivity of a black body; $T_{j}$ is the surface temperature; $F_{j}$ is the area of the th surface.

The author of the scientific discovery, A. Makarov developed a geometric, physical, mathematical model of an electric arc in SMEAF as an ionized cylindrical gas source of thermal radiation (Figure 3), and obtained formulas for calculating the thermal radiation of an arc on surfaces in SMEAF. Three of the sixteen derived formulas for calculating heat transfer in SMEAF shown in Figure 4. Subsequently, using copyright, the formula for calculating the thermal radiation of a cylindrical gas volume on a heating surface is called the first law of thermal radiation of a gas volume of Makarov.

\section{The Results of Using the Theory of Heat Transfer in the Practice of Operating Steel Melting Electric Arc Furnaces (SMEAF)}

The author developed a pioneering theory of heat transfer in SMEAF. The theory includes the integration of 16 differential equations and the derivation of 16 formulas for calculating heat transfer in SMEAF for any spatial position of the electric arc and heating surface.

The formulas derived allow one to determine the flow of thermal radiation from an arc to a metal bath, walls, SMEAF, calculate the electrical and technological modes of operation in which the arc is deepened into a metal bath and slag, its efficiency is increased, the energy consumption of the furnace is reduced, the specific energy consumption for smelting one-ton steel. The derived formulas and the heat transfer theory developed on their basis allowed us to develop 15 innovative designs of SMEAF and methods for melting steel in them, to explain the causes of uneven wear of the wall lining in chipboard (Figure 5). At the $\mathrm{V}$ International Forum on Intellectual Property in the Field of Metallurgical Technologies and Energy Support for Metallurgical Technologies, held in 2013 in Moscow, the inventor was awarded the silver medal of the forum.

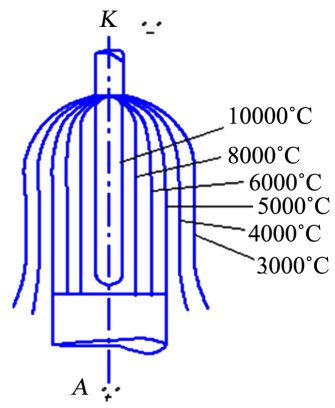

(a)

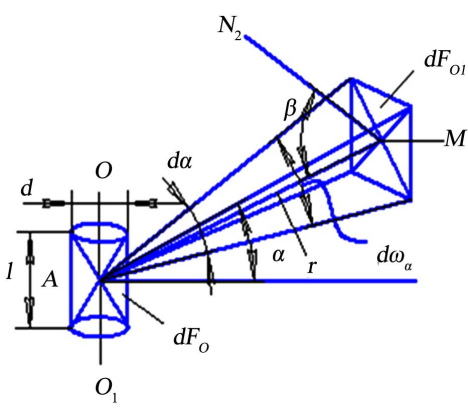

(b)

Figure 3. Electric arc and its isotherms (a); simulation of arc radiation by radiation of an elementary cylinder (b). 
(a)

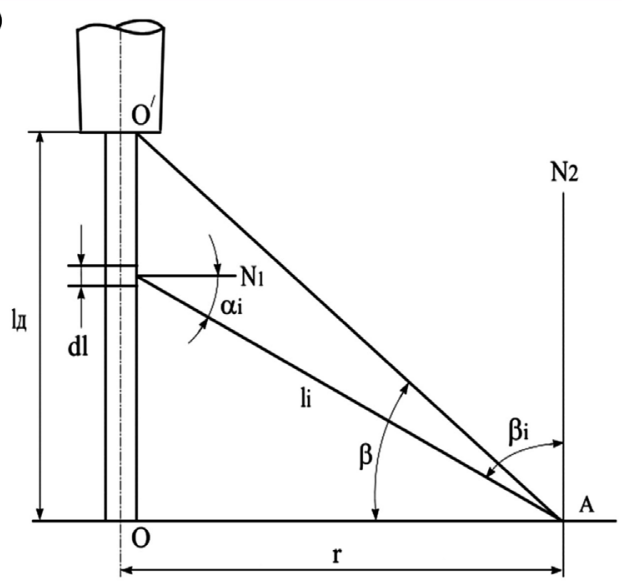

(b)

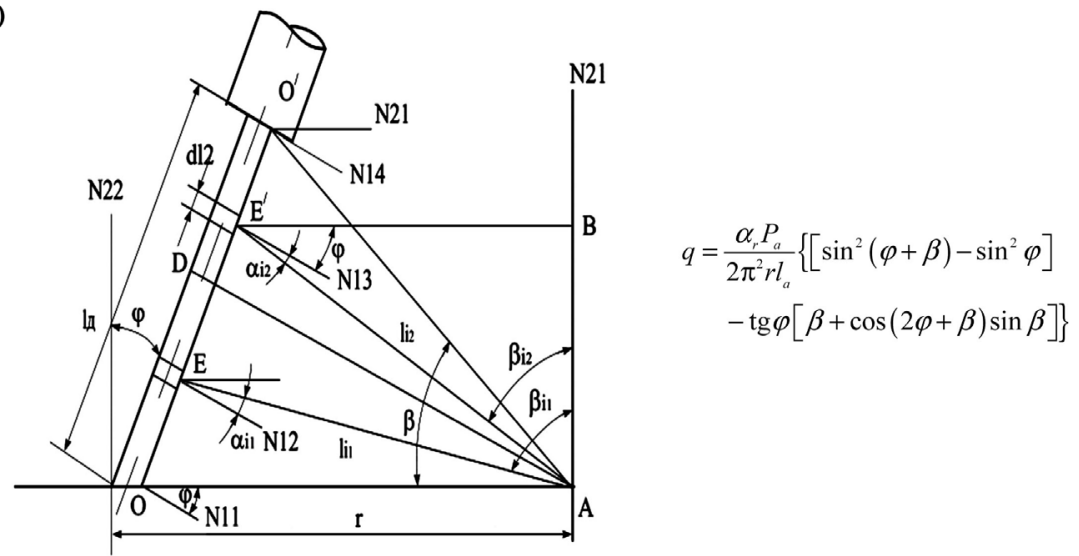

(c)

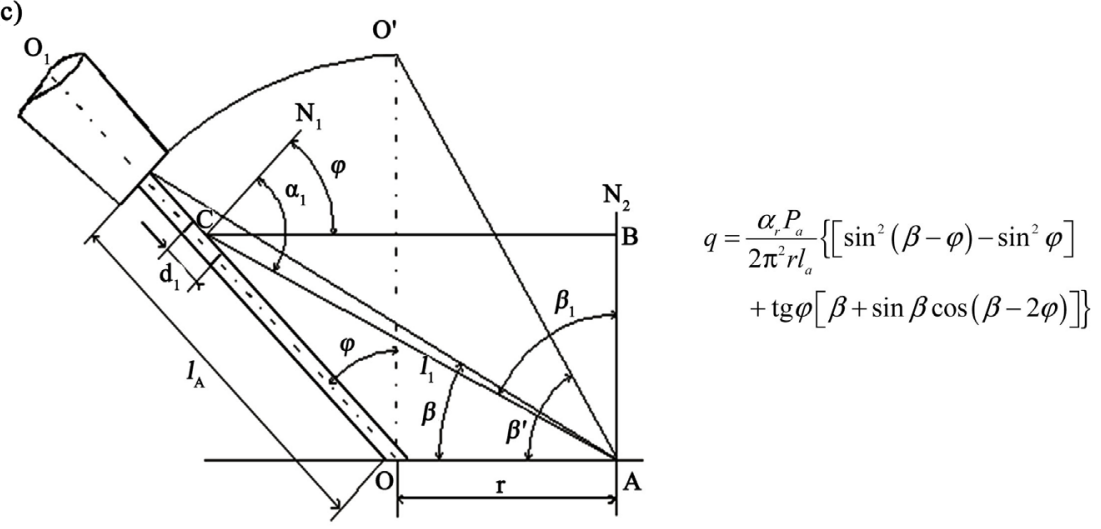

Figure 4. Radiation of the arc on the horizontal surface of the metal bath and the derived calculation formulas: vertical arc (a); the inclined arc and the outer sections of the metal bath (b); the inclined arc and the inner sections of the metal bath (c).

The author of the pioneer theory conducted experimental research at metallurgical plants in Russia, Severstal, Chelyabinsk, Orsk-Khalilovsky, Oskol electrometallurgical and others. Experimental studies have confirmed the truth of the developed theory. The calculated heat transfer data in furnaces and the experimental data on heat transfer in furnaces have high convergence: the calculated and experimental data do not differ by more than $10 \%$. 


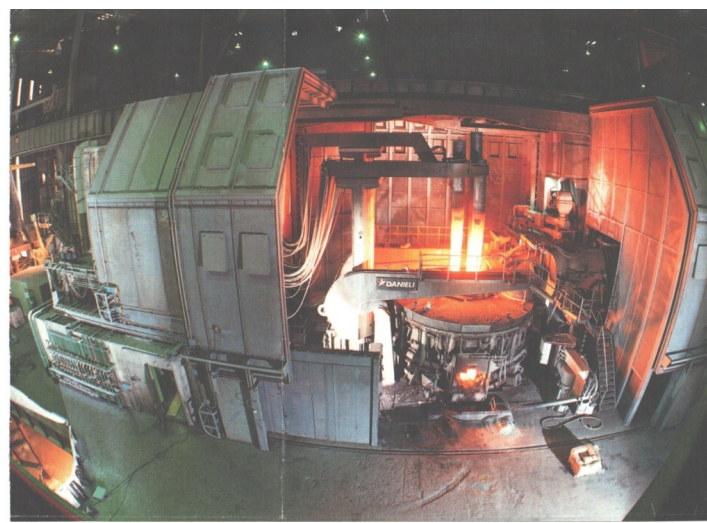

Figure 5. SMEAF-140, with a capacity of 140 tons, of the "Danieli" company.

More than 35 years developed by A. Makarov The theory of heat transfer in electric arc furnaces is used to train metallurgical students at NITU MISiS and all metallurgical universities and metallurgical departments of technical universities in Russia and universities in Russian-speaking countries abroad. The theory is used at all metallurgical enterprises in Russia to calculate and select rational energy-technological modes of operation of furnaces. The results of a forty-year theoretical and experimental study of the thermal radiation of ionized and non-ionized gas volumes, heat transfer in the arc and flare metallurgical furnaces, furnaces, and combustion chambers are presented by the author in a monograph [4] and in the training manual "A. Makarov Heat transfer in electric arc and flare metallurgical furnaces and power plants. St. Petersburg, publishing house 'Doe'. 2014384 pp”. Textbook Makarova A. N. It is the main textbook on heat transfer in electric arc furnaces and is recommended by UMO for education in metallurgy of the Ministry of Education and Science of the Russian Federation for university students. The textbook is used at universities in the metallurgical field and at the metallurgical departments of technical universities, as well as in metallurgical companies in Russia.

In Russia, metallurgical companies currently have installed over 50 hundred-ton steel-melting electric arc furnaces with a capacity of $90 \mathrm{MW}$ and a capacity of 1 million tons each. In the early 1990s, in these furnaces, the specific energy consumption was $450-460 \mathrm{kWh} / \mathrm{t}$, and the total consumption of $450-$ 460 million $\mathrm{kWh}$ per furnace. By 2015, due to technological factors and the proper organization of heat transfer in these furnaces, the specific energy consumption decreased to $350-360 \mathrm{kWh} / \mathrm{t}$, total to $350-360$ million $\mathrm{kWh}$ per year per furnace. Energy saving is 100 million $\mathrm{kWh}$ per furnace. A certain merit in saving energy in metallurgical companies belongs to A. N. Makarov, the developer of the theory of heat transfer in electric arc furnaces. The recognition of this fact is the results of the international exhibition Metal-Expo 2018. In November 2018, the 24th International Industrial Exhibition "Metal-Expo 2018" of the achievements of metallurgical companies, including metallurgical engineering companies, research institutes, universities and departments of the metallurgical field, was held at VDNH in Moscow. The exhibition was attended by 550 
companies from 32 countries, including 320 Russian and 230 foreign companies, some of which participated in the contests "High-tech developments, equipment, technologies, and products of ferrous and non-ferrous metallurgy" and "The best publication in the metallurgical industry". The Organizing Committee and the Competition Committee of the XXIV Metal-Expo 2018 International Industrial Exhibition included the heads of the following organizations and institutions: departments of the Ministry of Industry and Trade of Russia, the Russian Union of Metal Products Suppliers, metallurgical companies, research institutes and universities of the metallurgical field. Textbook "Makarov A.N. Heat transfer in electric arc and flare metallurgical furnaces and power plants. St. Petersburg: Doe, 2014, 384 pp." awarded the silver medal of the Metal-Expo 2018 exhibition in the nomination "The Best Edition in the Metallurgical Industry". NITU MISiS was awarded the gold medal for many years of training, the creation of materials and technologies, and in connection with the 100th anniversary.

Russian metallurgical companies operate steadily, successfully develop, sell products, both in Russia and abroad, industrialized countries of the European Union and the USA.

\section{Use of Scientific Discovery to Improve Flare Heating Furnaces}

Calculation of heat transfer in flare furnaces (Figure 6) according to the laws of thermal radiation of gas volumes (Table 1, Table 2) made it possible for the first time to obtain complete information about the flows of thermal radiation from the torch, heated walls, and vault falling onto all faces of ingots and other heated products. Hearth, combustion products, taking into account re-reflection and absorption (Figure 7), to identify the causes of uneven heating, to develop methods and heating devices that increase the uniformity of heating products, decrease heating time and fuel consumption, increases the productivity of furnace (obtained patents). The design of heating wells has not changed for 80 years (Figure 6). Patents for inventions of flare furnaces were obtained: 1) with 2 burners (Figure 8); II - with 6 burners (Figure 9); 2) with 12 burners and other patents (Figure 10, Figure 11), the descriptions of which are set forth by the author in monographs and textbooks.

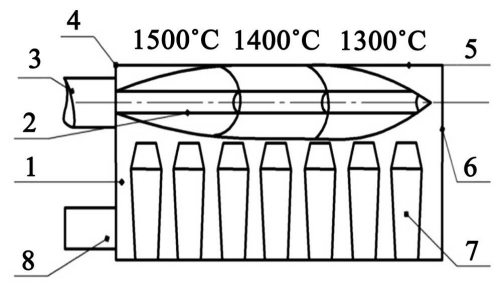

(a)

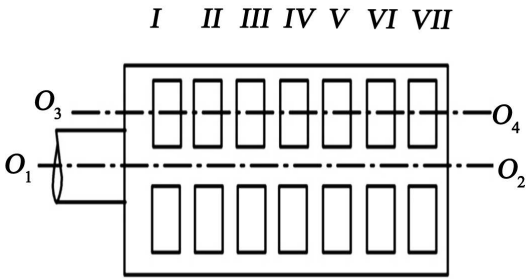

(b)

Figure 6. Scheme of the working space of the heating well (a) and the placement of ingots in it (b): I - VII-numbers of rows of ingots, 1-chamber; 2-torch; 3-burner; 4-frontal wall; 5-arch; 6-back wall; 7-ingots; 8-channels. 


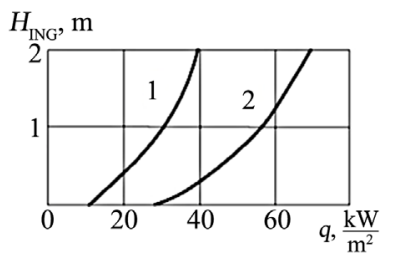

(a)

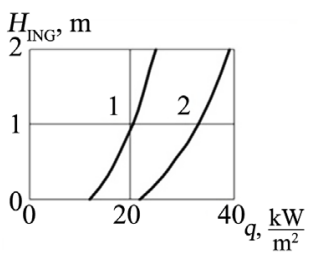

(b)

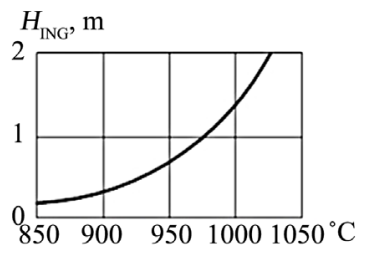

(c)

Figure 7. The graph of the distribution of total heat fluxes along the height of the side surface of the ingots facing the surface of the walls (a) and to the axis $\mathrm{O}_{1} \mathrm{O}_{2}$ (b); A: 1 -in height I, II, IV rows; 2-according to the height of ingots III - V, VII; b: 1-by the height of ingots of I, II, VI, VII rows; 2-by height of ingots of the III - V rows; (c)-temperature change along the height of the ingots at a distance of $80 \mathrm{~mm}$ from the surface during heating.

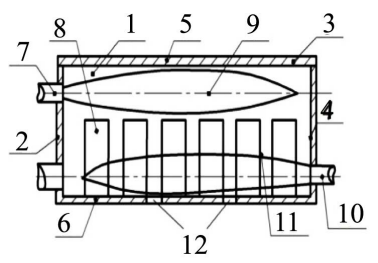

(a)

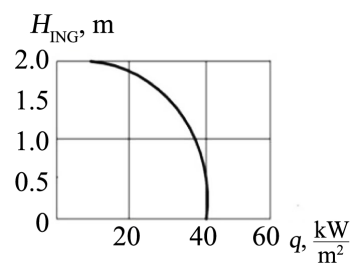

(c)

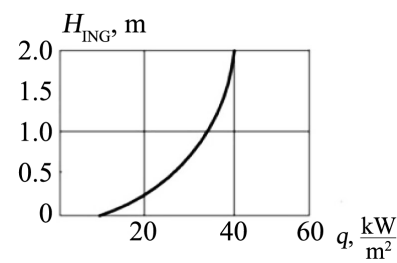

(b)

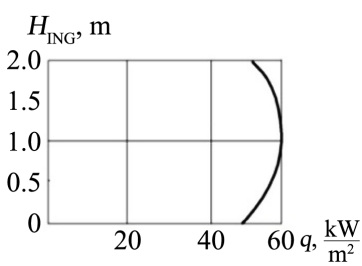

(d)

Figure 8. Scheme of a regenerative heating well with two flares (a) and distribution of average heat fluxes along the height of the ingots during operation of the upper burner (b), lower burner (c) of the upper and lower burners together (d).

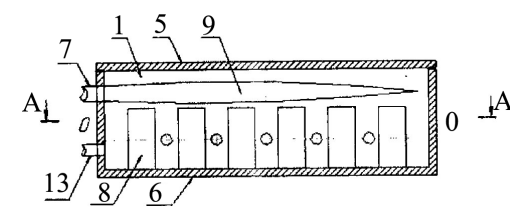

(a)

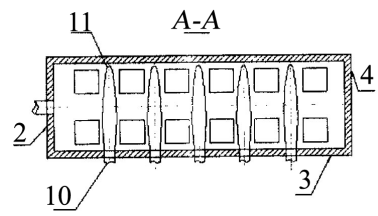

(b)

Figure 9. Recuperative well, side view (a); top view (b).

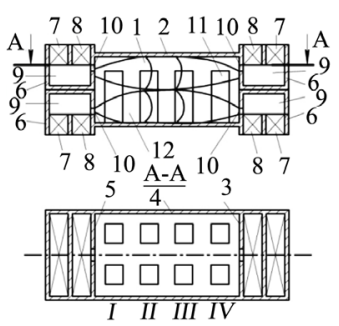

(a)

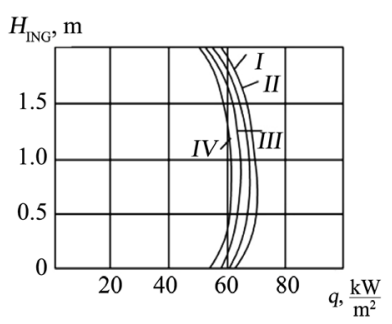

(b)

Figure 10. Scheme of a regenerative heating well with a block of regenerators in two tiers (a) and the distribution of the height of the ingots of integral heat fluxes (b). 


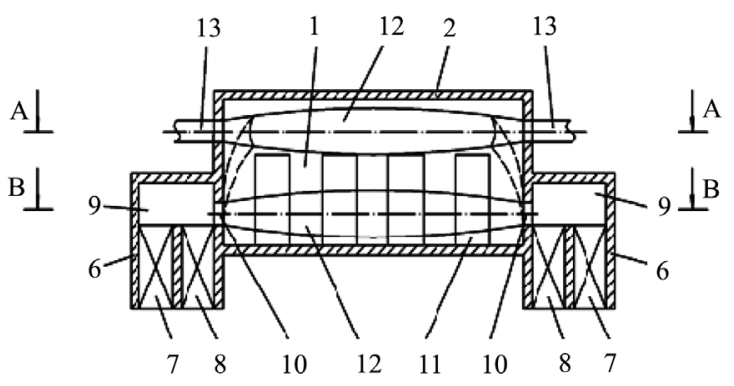

Figure 11. Scheme of a regenerative heating well with upper and lower torches.

\section{Use of Scientific Discovery to Study and Improve Heat Transfer in the Furnaces of Steam Boilers}

According to the laws of heat radiation of gas volumes and the calculation method developed on their basis for heat transfer in flare furnaces, and combustion chambers, heat transfer is calculated in the furnace of a steam boiler, of a power unit with a capacity of $800 \mathrm{MW}$ and other power units. The results of the calculation of heat transfer in the furnace of a steam boiler typical normative characteristic of the boiler (TGMP-204) are presented in Figure 12. The distribution of torch radiation fluxes and deposits in the pipes along the perimeter and height of the furnaces are substantially uneven, which negatively affects the operation of the boiler (Figure 12(b)): the boiler downtime for repairs and pipe flushing from in-pipe deposits increases.

The design of the furnaces of steam boilers in which the unevenness of heat fluxes, in-pipe deposits is reduced, the number of repairs and downtimes of the boiler is reduced (Figure 13).

The calculation according to the laws of thermal radiation of gas volumes made it possible for the first time to obtain complete information about the torch thermal radiation fluxes incident on the front, rear, sidewalls along the perimeter and height of the furnaces, on the reasons for the unevenness of deposits along the perimeter and height of the furnaces, the uneven formation of vapor in the pipes, and the causes of burnout burner devices, and other physical phenomena occurring in the furnaces of steam boilers. The author has developed patented innovative fire chambers of steam boilers [12] [13] [14] [15] in which the above mentioned negative phenomena occurring in fire chambers are reduced, their description is described in textbooks, monographs, articles [16] [17] [18] [19].

\section{Use of Scientific Discovery to Study and Improve Heat Transfer in the Combustion Chambers of Gas Turbine Plants}

According to the developed and set out in Table 2 methodology calculated the heat transfer in combustion chambers (CC) Gas turbine plants (GTP with a capacity of 4.25 MW. Torch capacity 16.28 MW. The calculation results are shown in Figure 14. 

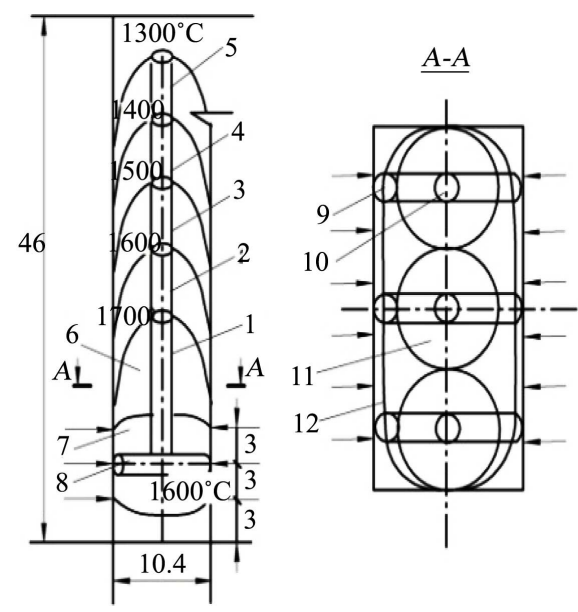

(a)

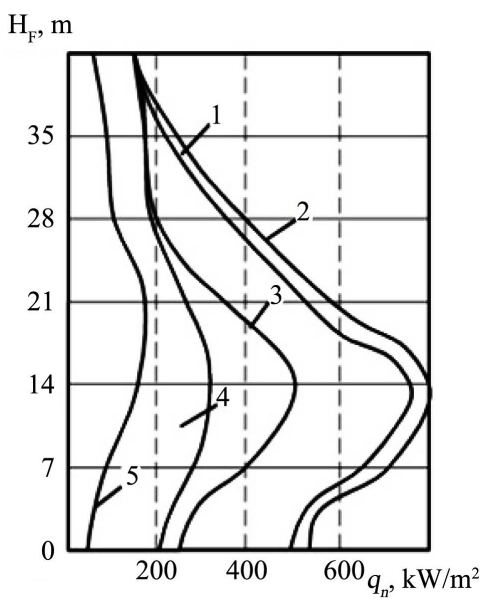

(b)

Figure 12. Distribution of isotherms in the furnace of the steam boiler TGMP-204 (a), distribution of the density of the total radiation flux along the walls of the furnace (b): 1 -along the vertical axis of symmetry of the front wall; 2-the same, the measurement result; 3-along the vertical axis of symmetry of the sidewall; 4-along the vertical axis at the periphery of the sidewall; 5-along the vertical axis on the periphery of the front wall.

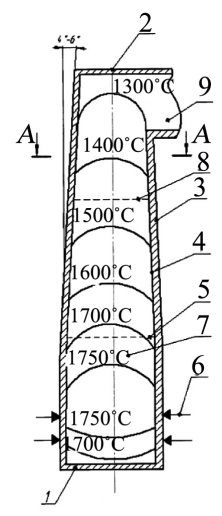

(a)

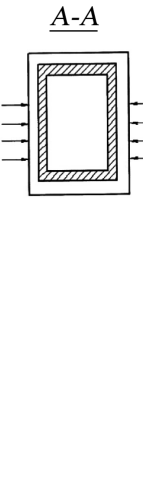

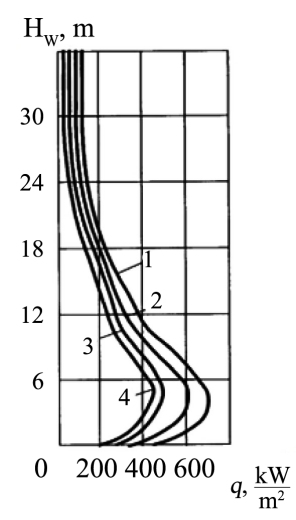

(b)

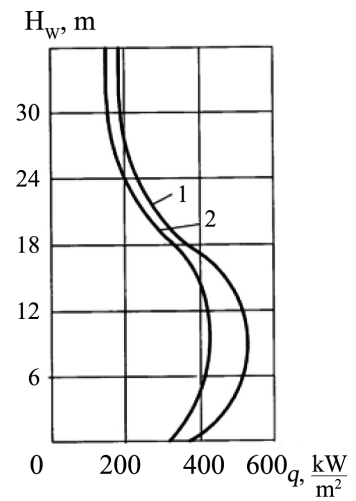

(c)

Figure 13. Patent for the invention: the combustion chamber of a steam boiler for burning gas oil with tilting part of the walls inward (a); the calculated distribution of the heat flux of the torch before reconstruction (b); after reconstruction (c).

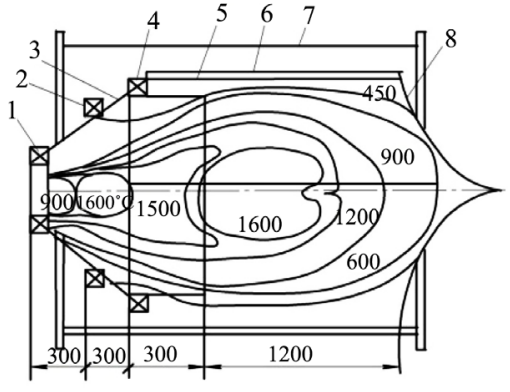

(a)

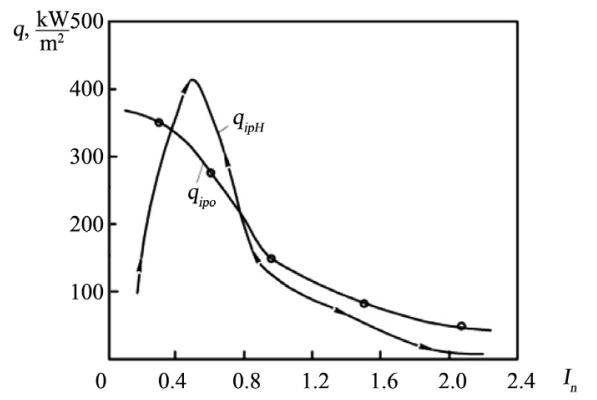

(b)

Figure 14. The diagram of the combustion chamber and the distribution of isotherms over the volume of the flame (a); the distribution of the densities of the heating and cooling flows along the length of the flame tube (b). 
An analysis of the density distribution of the resulting heating fluxes along the length of the combustion chamber showed their considerable unevenness: from $380 \mathrm{~kW} / \mathrm{m}^{2}$ on the surfaces of a large cone to $120 \mathrm{~kW} / \mathrm{m}^{2}$ in the middle ring of the flame tube and up to $8 \mathrm{~kW} / \mathrm{m}^{2}$ in the last annular zone of the flame tube at the mixer. At a distance of $0.5 \mathrm{~m}$ from the burner, the cooling of the combustion chamber is unsatisfactory since the resulting heat fluxes from the flame exceed the heat fluxes for cooling the air. For reliable operation of the combustion chamber, correction of the cooling air parameters along the length of the combustion chamber is required.

The densities of the thermal radiation incident from the torch were calculated on the horizontal heating surface and the burner device for different torch lengths (Figure 15).

As can be seen from the calculation results, an increase in the length of the torch with a constant power of the torch entails a decrease in heat fluxes to the embrasure and burner. With an increase in the torch length, 2.7 times from 3 to $8 \mathrm{~m}$, the density of heat fluxes to the burner decreased 4 times from 480 to 120 $\mathrm{kW} / \mathrm{m}^{2}$. The calculation data are confirmed by experimental studies on the furnaces of steam boilers TGMP-314 of a $300 \mathrm{MW}$ power unit at TPP-21, TPP-23 Mosenergo, and Konakovskaya TPP: with an increase in the length of the flame at constant power from 3 to $5 \mathrm{~m}$, i.e. 1.7 times, the density of the heat fluxes of the torch radiation to the burner device decreased by 2 times from $1500-1400$ $\mathrm{kW} / \mathrm{m}^{2}$ to $700-750 \mathrm{~kW} / \mathrm{m}^{2}$, the life of the burners increased by 4 times from 6 12 months to 2 - 4 years.

Calculations according to the laws of thermal radiation of gas volumes and the methodology developed on their basis made it possible for the first time to obtain complete calculated information about the distribution of torch radiation fluxes over the surface of a flame tube, a burner of a gas turbine installation, about the magnitude and location of the maximum heat fluxes of a torch on the surface of a flame tube for organizing effective cooling and increase the service life of the GTP flame tube.

At present, the temperature of gases in the compressor station and gas turbine is $1400^{\circ} \mathrm{C}-1600^{\circ} \mathrm{C}$ (Figure 16). The costs of creating the gas turbine engine AL-31F amounted to several billion US dollars. The creation time is 10 years. About $10 \%$ of this amount is accounted for by the design and experimental

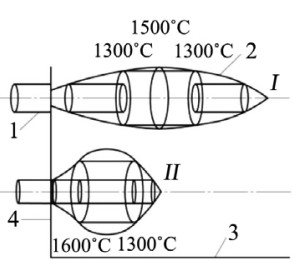

(a)

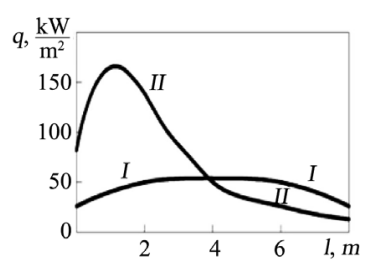

(b)

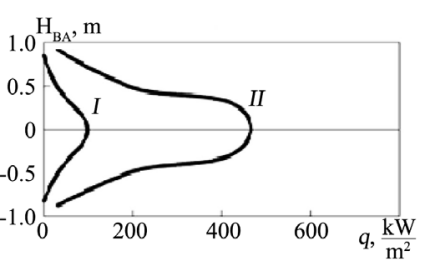

(c)

Figure 15. Location and power of the torch I and II: $\mathrm{L}_{\mathrm{t} 1}=8 \mathrm{~m}, \mathrm{l}_{\mathrm{t} 2}=3 \mathrm{~m}, \mathrm{R}_{\mathrm{t}}=5 \mathrm{MW}$ (a); distribution of heat fluxes from the torch along the horizontal heating surface (b) and along the surface of the embrasure (c). 


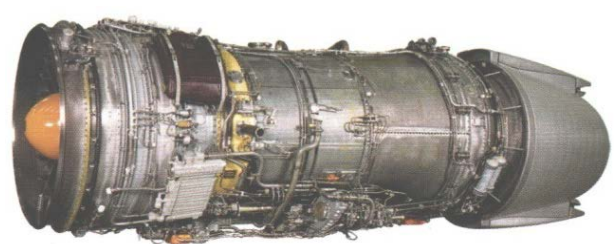

(a)

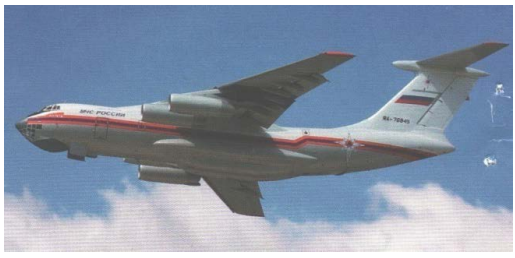

(b)

Figure 16. Gas turbine engine D-30KP-2, with a thrust of 12,000 kg (a); D-30KP-2 on an IL-76 aircraft, with a carrying capacity of 50 tons (b).

studies of the composite structure, testing of the new design of the structure before its operational destruction, followed by changes in the design and the use of new alloys to achieve durability, again testing the design of the structure before destruction, the creation of the next prototype of the structure with heat-resistant coating and such work continues until the creation of a sample of the COP with good performance properties, and increased service life. The design, research, manufacture, testing of a prototype CC continues for several years until the creation of a CC sample with high heat resistance, reliability, and durability.

When using the developed methodology for calculating heat transfer in gas turbine compressor stations, gas turbine engine, based on the open laws of thermal radiation of gas flare volumes, the gas generator creation time can be reduced by 2 - 3 times, the costs of creating a gas compressor by $20 \%-30 \%$, and the creation of a gas turbine by $5 \%-8 \%$ The savings in the creation of a new generation gas turbine engine using the open laws of thermal radiation of gas volumes of flares and the developed methodology for calculating heat transfer in a compressor station can be several hundred million dollars.

\section{Fundamental Laws of Physics}

All the fundamental laws of physics, the laws of Newton, Hooke, Fourier, and Ohm (Table 3), thermal radiation of gas volumes of Makarov (Table 1) and others, have a relatively simple spelling, they have few calculated parameters, but this is their fundamental nature, universality, and inclusiveness, multidisciplinary, accurate description of natural phenomena.

The fundamental laws of physics are the basis for the development of theories, calculation methods, with the help of which all existing types of engineering and technologies were created in the 20th - 21st centuries, electrification, mechanization, automation, computerization of industry, agriculture and everyday life were carried out.

\section{Conclusions}

With the scientific discovery of the laws of thermal radiation of gas volumes of torches and electric arcs, it became possible for the first time to calculate the heat transfer in electric arc [20] [21] [22] [23] and torch furnaces, and combustion chambers with high accuracy, to improve the heat transfer and design of electric 
Table 3. Some fundamental laws of physics: Newton's laws, Stefan-Boltzmann, Ohm, Planck, Wine, Einstein, Bohr postulates.

\begin{tabular}{|c|c|c|}
\hline The laws & Math record of law & Formulation of the law \\
\hline 1) Newton's law & $a=0$ & $\begin{array}{l}\text { Anybody, as long as it remains } \\
\text { isolated, retains its state of rest or } \\
\text { uniform rectilinear motion (the } \\
\text { acceleration of the body a is zero). }\end{array}$ \\
\hline 2) Newton's law & $m \boldsymbol{a}=\boldsymbol{F}$ & $\begin{array}{l}\text { The product of the mass of a } \\
\text { body by the acceleration it } \\
\text { received from the action of the } \\
\text { force A of another body, } \\
\text { equal to the force A }\end{array}$ \\
\hline 3) Newton's law & $\boldsymbol{F}_{12}=-\boldsymbol{F}_{21}$ & $\begin{array}{l}\text { There is always an equal and } \\
\text { opposite reaction to action }\end{array}$ \\
\hline $\begin{array}{l}\text { Stefan-Boltzmann } \\
\text { law of thermal } \\
\text { radiation of solids }\end{array}$ & $q_{12}=\frac{\varphi_{12} \varepsilon_{1} C_{s} F_{1}}{F_{2}} x\left[\left(\frac{T_{1}}{100}\right)^{4}-\left(\frac{T_{2}}{100}\right)^{4}\right]$ & $\begin{array}{l}\text { The density of the flux of thermal } \\
\text { radiation } \mathrm{q}_{12} \text { incident from body } 1 \\
\text { to body } 2 \text { is directly proportional } \\
\text { to the temperature difference of } \\
\text { the bodies to the fourth degree. }\end{array}$ \\
\hline Ohm's law & $I=\frac{U}{R}$ & $\begin{array}{l}\text { The current flowing in the } \\
\text { conductor is directly proportional } \\
\text { to the voltage applied to it and } \\
\text { inversely proportional to the } \\
\text { resistance of the conductor. }\end{array}$ \\
\hline Planck's Law & $E_{0 \lambda}=c_{1} \lambda^{-5}\left(\mathrm{e}^{c_{2} / \lambda t}-1\right)$ & $\begin{array}{l}\text { The density of the heat radiation } \\
\text { flux in the blackbody is inversely } \\
\text { proportional to the wavelength } \\
\text { and directly proportional to the } \\
\text { body temperature. }\end{array}$ \\
\hline Wine Law & $\lambda_{\mathrm{M}} T=2879.8$ & $\begin{array}{l}\text { The wavelength at which the } \\
\text { blackbody radiation density reaches } \\
\text { its maximum value is inversely } \\
\text { proportional to body temperature. }\end{array}$ \\
\hline $\begin{array}{l}\text { Einstein's law for } \\
\text { photoelectric effect }\end{array}$ & $h v=A_{\mathrm{e}}+\frac{m V^{2}}{2}$ & $\begin{array}{l}\text { The energy of a photon descending } \\
\text { to the cathode, followed by the } \\
\text { emission of an electron by the } \\
\text { cathode, is equal to the exit energy } \\
\text { and the kinetic energy of the } \\
\text { electron. }\end{array}$ \\
\hline Bohr's Postulates & - & $\begin{array}{l}\text { 1) In a stationary state, the atom } \\
\text { does not emit. } \\
\text { 2) When an atom transfers from } \\
\text { a state with a higher energy to a } \\
\text { state with a lower energy, when an } \\
\text { electron in an atom jumps from an } \\
\text { orbit more remote from the } \\
\text { nucleus, a quantum of } \\
\text { electromagnetic, thermal } \\
\text { radiation is emitted } \\
\text { 3) In a stationary state, an electron } \\
\text { moves in a certain orbit, } \\
\text { a Coulomb force acts on an } \\
\text { electron in an atom. }\end{array}$ \\
\hline
\end{tabular}


arc and torch furnaces of industrial enterprises around the world, combustion furnaces, combustion chambers of gas turbine plants of power plants, save million $\mathrm{kWh}$ of electricity and million tons of liquid, gaseous, pulverized fuel, reduce pollutant emissions in societies, reduce the technological pressure on the environment in many cities around the world.

For the scientific discovery of the laws of thermal radiation of gas volumes by the author of a similar significance, for the discovery by Win and Planck of the laws of thermal radiation of solids, an absolutely black body, to Win in 1911, Planck was awarded the Nobel Prize in Physics in 1918. For Einstein's discovery of the law of the photoelectric effect of radiation in 1921, which was similar insignificance, and for the development of the theory of the atom and radiation from it, Bohr was awarded the Nobel Prize in physics in 1922. The laws of thermal radiation of gas volumes, as well as the laws of thermal radiation of solids, blackbody, belong to the fundamental laws of physics, its section "Quantum Physics of Thermal Radiation". Bohr was the last scientist to receive the Nobel Prize in Physics for discovering the fundamental laws of physics. The discovery of the fundamental laws of physics is an outstanding event in the life of mankind, which occurs once every 50 - 80 years. Confirmation of this fact is physics textbooks for schools and universities, which set out a little more than 30 laws discovered by mankind over 3 thousand years, starting from the III century BC, from the law of Archimedes and ending with the last fundamental laws, postulates discovered by Bohr in 1913.

\section{Conflicts of Interest}

The author declares no conflicts of interest regarding the publication of this paper.

\section{References}

[1] Blokh, A.G., Zhuravlev, A.N. and Rozhkov, A.N. (1991) Radiant Heat Transfer: A Handbook. Energoatomizdat, Moscow.

[2] Siegel, R. and Howell, G. (1975) Thermal Radiation Heat Transfer. Mir, Moscow.

[3] Telegin, A.S. (1993) Thermotechnical Calculations of Metallurgical Furnaces: A Textbook. Metallurgy, Moscow.

[4] Makarov, A.N. and Svenchanskiy, A.D. (1992) Optimal Operating Conditions of Arc Steel Melting Furnaces. Energoatomizdat, Moscow.

[5] Makarov, A.N. (2014) Heat Transfer in Electric Arc and Torch Metallurgy Furnaces and Energy Plants. Lan, St. Petersburg.

[6] Makarov, A.N. (2014) Theory of Radioactive Heat Exchange in Furnaces, Fireboxes, Combustion Chambers Is Replenished by Four New Laws. Science Discovery, 2, 34-42. https://doi.org/10.11648/j.sd.20140202.12

[7] Makarov, A.N. (2015) Radiation from Large Gas Volumes and Heat Exchange in Steam Boiler Furnaces. Power Technology and Engineering, 49, 196-201. https://doi.org/10.1007/s10749-015-0598-y

[8] Makarov A.N. (2016) Flare Temperature and Nitrogen Oxide Emission Reduction 
and Heat Transfer in the TGMP-314I Steam Boiler Firebox. Power Technology and Engineering, 50, 200-203. https://doi.org/10.1007/s10749-016-0683-X

[9] Makarov, A.N., Okuneva, V.V. and Galicheva M.K. (2017) Influence of the Length of a Torch Tongue on Heat Flow in a Burner Device. Power Technology and Engineering, 51, 445-450. https://doi.org/10.1007/s10749-017-0853-5

[10] Makarov, A.N. (2019) The Laws Heat Radiation from Solids, Gas Volumes and the Fundamental Laws of Physics. Journal of Applied Physics \& Nanotechnology, 2, $1-5$.

[11] Makarov, A.N. (2019) Calculation of Heat Transfer in Torch Furnaces under the Laws of Radiation from Gas Volumes. Journal of Applied Physics \& Nanotechnolo$g y, 2,6-16$.

[12] Makarov, A.N., Galicheva, M.K. and Kuznetsov, A.V. (2017) Patent 2613539, A Furnace for Burning Gas and Reduced Fuel Oil. Inventions, 8, 31-32.

[13] Makarov, A.N., Neverov, F.N. and Kuznetsov, A.V. (2014) Patent 2547675, A Furnace for Burning gas and Reduced Fuel Oil. Inventions, 10, 17-18.

[14] Makarov, A.N. (2018) Radiation of Gas Volumes and Calculations of the Torch in Furnaces. Electric Generating Station, 4, 42-50.

[15] Makarov, A.N. and Shevchenko, M.N. (2010) Patent 2400668, A Furnace for Burning Gas and Reduced Fuel Oil. Inventions, 27, 10-11.

[16] Makarov, A.N. (2017) Fundamental Laws of Physics and Calculation of Heat Transfer in Combustion Chambers of Gas-Turbine Plants. World Journal of Engineering and Technology, 5,358-375. https://doi.org/10.4236/wjet.2017.53030

[17] Makarov, A.N. (2019) Calculations of Heat Radiation in from Gas Volumes (Part. II) Calculations of Radiation from the Torch on the Burner. JP Journal of Heat and Mass Transfer, 16, 43-45. https://doi.org/10.17654/HM016010043

[18] Makarov, A.N. (2019) Calculations of Heat Transfer in Torch Furnaces. JP Journal of Heat and Mass Transfer, 18, 145-165. https://doi.org/10.17654/HM018010145

[19] Makarov, A.N (2018) Calculations of Heat Transfer in the Furnaces of Steam Boilers According in the Laws of Radiation of Gas Volumes. In: Volkov, K., Ed., Heat Transfer-Models, Method and Applications, InTechOpen, London, 111-130. https://doi.org/10.5772/intechopen.75529

[20] Makarov, A.N. (2017) Changingarcs Efficiency during Melting in EAF. Metallurgist, 58, 55-58.

[21] Makarov, A.N. (2019) Effect of the Architecture on Energy Efficiency of Electric Arc Furnaces of Conventional and Consteel Desings. Metallurgist, 62, 882-891. https://doi.org/10.1007/s11015-019-00743-9

[22] Makarov, A.N. (2019) Calculation and Analysis of Energy Parameters of Meltings in Eafts of Conventional and Consteel Desing. Metallurgist, 62, 974-978. https://doi.org/10.1007/s11015-019-00733-x

[23] Makarov, A.N. (2019) Calculation and Analysis of the Relationship between the Efficiency and Position of Electric Arcs Furnaces (EAF) of Smaller and Larger Capacity. Part I. Calculation and Analysis of the Relationship between Arc Efficiency and Power Consumption. Metallurgist, 63, 341-349. https://doi.org/10.1007/s11015-019-00829-4 